\title{
Study of Annealing Effect on Characteristics of NiFeW Alloy Thin Films
}

\author{
Dr. T. Baskar ${ }^{*}$, Dr. A. Shaji George ${ }^{2}$, Bashiru Aremu ${ }^{3}$, A. S. Hovan George ${ }^{4}$ \\ ${ }^{I}$ Post -Doctoral Researcher, Department of Physics, Crown University, Int'l. Chartered Inc. \\ (CUICI, ) Argentina Campus, South America. \\ ${ }^{2}$ Professor, Department of Physics, Shree Sathyam College of Engineering and Technology, \\ Sankari Taluk, Salem District, Tamil Nadu, India \\ ${ }^{3}$ Professor, Department of Information and Communication Technology, Crown University, Int'l. Chartered Inc. \\ (CUICI), Argentina Campus, South America. \\ ${ }^{4}$ Vice Chancellor, Crown University, Int'l. Chartered Inc. (CUICI) Argentina Campus, South America. \\ ${ }^{5}$ Masters IT Solutions, Chennai, Tamil Nadu, India.
}

\begin{abstract}
Alloy thin films of NiFeW were prepared using electroplating at room temperature. Then electroplated NiFeW thin films was annealed at $200{ }^{\circ} \mathrm{C}$. NiFeW deposited films are textured with FCC phase preferred orientation. They were exposed to morphological, structural and mechanical characterization analysis. NiFeW films were bright and uniformly coated on the surface. Also the deposits of NiFeW films were in nano scale and the average crystalline size was around 70 $\mathrm{nm}$. The micro hardness of NiFeW was $142 \mathrm{VHN}$ after annealing.
\end{abstract}

Keywords - Electroplating; Crystalline Size; Ni-B; X-ray Diffraction; Electrolytic Bath; VHN; VSM; SEM.

\section{Introduction}

Electro deposition is an electrochemical procedure for changing the structure of a surface. Electro deposition is one of the most promising deposition methods because of its fine control, low cost, simple setup, and possible compatibility [1-4].To create NiFeW alloy thin films, a variety of physical and chemical techniques can be applied, including thermal breakdown, co-precipitation, spray pyrolysis, and electro deposition [5-7]. The introduction of nickel boron alloy sheets in MEMS would improve sensing, storage, and transduction capabilities, as well as adaptability and performance of existing MEMS [8-10]. Nickel is a well-known boron-containing soft magnetic material [11-13]. NiFeW alloy thin films are used in transformers, inductors, magnetic shields, magnetic amplifiers and memory storage devices because of the best soft magnetic properties. This study looked into the effects of annealing on NiFeW films.

\section{Experimental Part}

Electrodeposition of NiFeW alloy films was carried out using electrolyte baths containing sodium tungstate $(10 \mathrm{~g} / \mathrm{l})$, nickel sulphate $(30 \mathrm{~g} / \mathrm{l})$, ferrous sulphate $(15 \mathrm{~g} / \mathrm{l})$, ammonium sulphate $(40 \mathrm{~g} / \mathrm{l})$, boric acid $(10 \mathrm{~g} / \mathrm{l})$, and saccharin $(10 \mathrm{~g} / \mathrm{l})$ and was carried out at room temperature ( 30 o C). It took 15 minutes to conclude the deposition. The cathode and anode in this investigation [14-16] were copper and stainless steel substrates with dimensions of $1.5 \mathrm{~cm} \mathrm{x}$ $7.5 \mathrm{~cm}$. The $\mathrm{pH}$ of the electrolytic solution was adjusted to 6.0 by adding ammonia solution, and the electroplating technique was carried out at a current density of $3 \mathrm{~mA} / \mathrm{cm} 2$.
The copper or cathode was normally removed from the bath after 15 minutes and dried for a few minutes [17]. The thin $\mathrm{NiFeW}$ sheets were then electroplated and annealed at 200 degrees Celsius. The surface nature of NiFeW films was described using a scanning electron microscope. Energy-dispersive X-ray spectroscopy was used to look at the atomic composition of film deposits, and X-ray diffraction was used to look at the crystal structure of the deposits. Vickers Hardness Test was used to determine the micro hardness of the films.

\section{Result and Discussion}

\subsection{Elemental Composition of NiFeW Thin Films}

The elemental composition of $\mathrm{NiFeW}$ films was determined by EDAX analyser. The obtained data analyser are shown in Table 1. From result, after annealing, nickel increased and tungsten decreased.

Table 1. EDAX analysis of thin films

\begin{tabular}{|c|c|c|c|c|}
\hline $\begin{array}{c}\text { S. } \\
\text { No }\end{array}$ & Condition & Ni Wt\% & Fe Wt\% & W \\
\hline 1. & $\mathrm{NiFeW}\left(30^{\circ} \mathrm{C}\right)$ & 48.71 & 37.42 & 13.87 \\
\hline 2 & $\begin{array}{c}\mathrm{NiFeW}(\text { Annealed } \\
\left.200^{\circ} \mathrm{C}\right)\end{array}$ & 53.96 & 33.74 & 12.30 \\
\hline
\end{tabular}

\subsection{Morphological Observation}

Surface appearance of $\mathrm{NiFeW}$ thin films at $30^{\circ} \mathrm{C}$ and annealed thin film were analysed by Scanning Electron Microscope (SEM) images and they are shown in Fig 1.

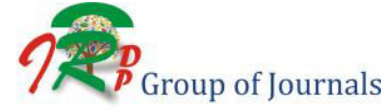


The thin films are bright and uniformly coated on the surface. They are crack free by appearance.

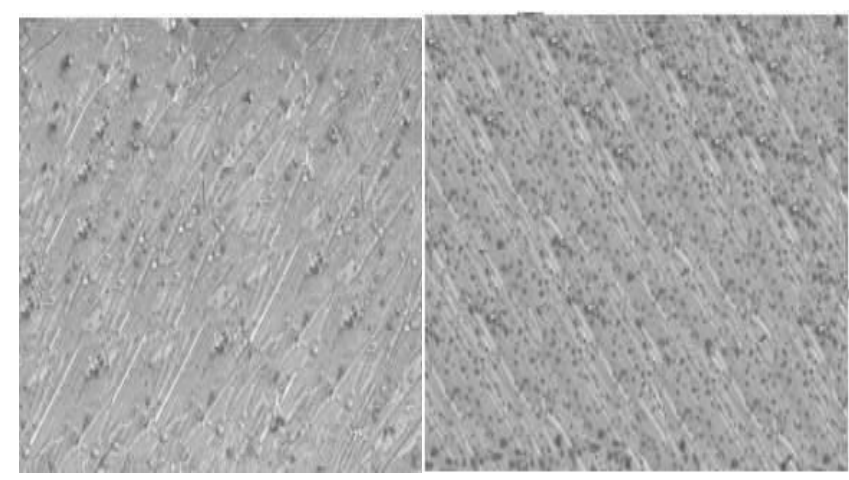

(a)

(b)

Fig.1: SEM images of thin films (a) $\mathrm{NiFeW}\left(30^{\circ} \mathrm{C}\right)(\mathrm{b})$ $\mathrm{NiFeW}$ (Annealed $200^{\circ} \mathrm{C}$ )

\subsection{Structural Characters}

Structural characteristic (from XRD Data) results of deposited materials prepared with temperature $30^{\circ} \mathrm{C}$ and annealed thin film are shown in figure 2. From XRD pattern of $\mathrm{NiFeW}$, crystal formation of deposits can be concluded. The size of crystals of can be determined by formula,

$$
\text { Crystal Size }(\mathrm{D})=(0.955 \lambda) / \beta \operatorname{Cos} \theta
$$

Where, $\lambda$ is wavelength of incident light and $\beta$ is FWHM at $2 \theta$. The XRD results of NiFeW films shows face centred cubic phase with three diffraction peaks. The nano crystallite deposits was obtained.

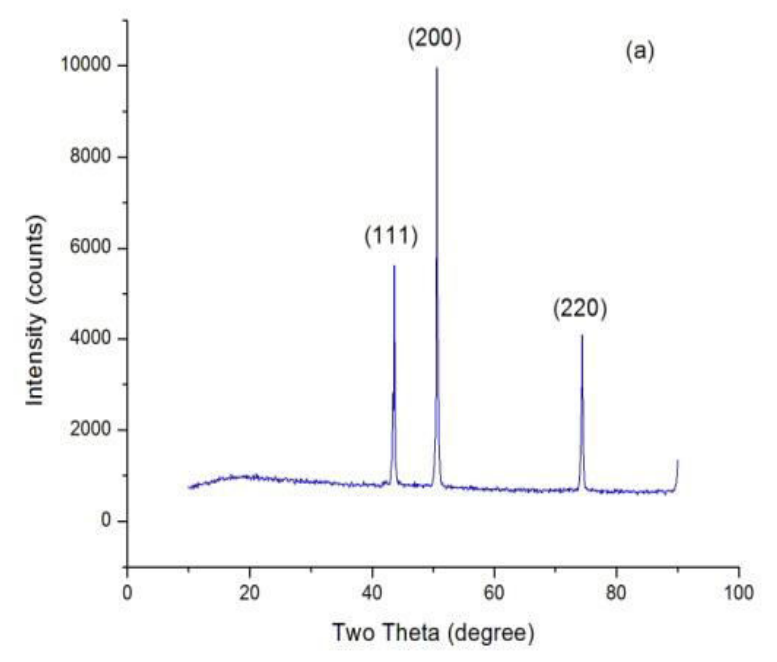

(a) (b)

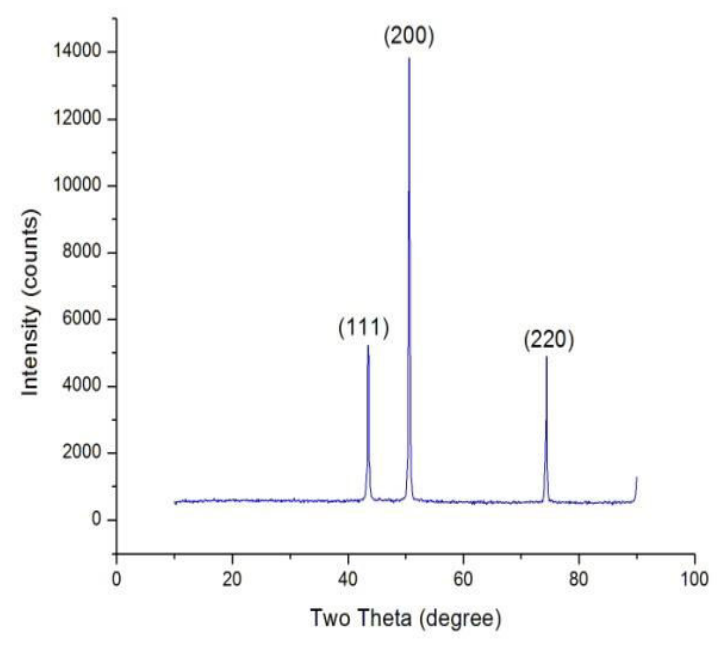

(b)

Fig.2: XRD patterns (a) $\mathrm{NiFeW}\left(30^{\circ} \mathrm{C}\right)$ (b) NiFeW (Annealed $200^{\circ} \mathrm{C}$ )

The crystallite sizes of $\mathrm{NiFeW}$ deposits are tabulated in table 2 . Annealing process decreases the crystal size.

Table 2. NiFeW alloy films -Structural properties

\begin{tabular}{|c|c|c|c|c|}
\hline $\begin{array}{c}\text { S. } \\
\text { No }\end{array}$ & Condition & $\begin{array}{c}\mathbf{2 \theta} \\
(\mathbf{d e g})\end{array}$ & $\begin{array}{c}\mathbf{d} \\
\left(\mathbf{A}^{\mathbf{0}}\right)\end{array}$ & $\begin{array}{c}\text { Particle } \\
\text { Size(D) } \\
(\mathbf{n m})\end{array}$ \\
\hline 1 & $\begin{array}{c}\mathrm{NiFeW}\left(30^{\circ} \mathrm{C}\right. \\
\text { \& without } \\
\text { denine })\end{array}$ & 43.65 & 1.7407 & 79.06 \\
\hline 2 & $\begin{array}{c}\text { NiFeW } \\
(\text { Annealed } \\
\left.200^{\circ} \mathrm{C}\right)\end{array}$ & 45.03 & 1.6134 & 61.26 \\
\hline
\end{tabular}

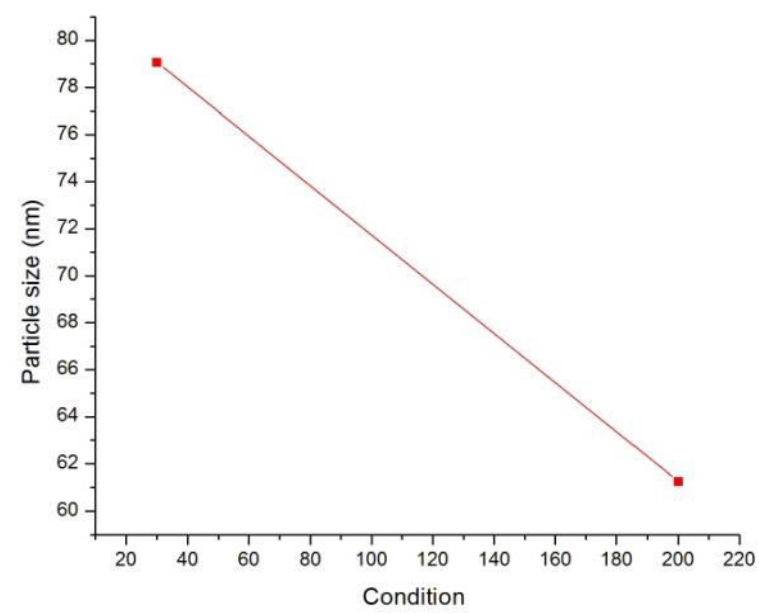

Fig.3: Particle size changes with condition 


\subsection{Mechanical Properties}

Micro hardness measurement of deposits was done by Vickers hardness tester. The hardness values of thin films at room temperature $30^{\circ} \mathrm{C}$ and annealed thin film are shown in table 3. Annealing process increases the hardness, because of onset formation of crystal deposits during electro deposition process.

Table 3. NiFeW alloy films -Hardness

\begin{tabular}{|c|c|c|}
\hline S.No & Condition & Hardness VHN $)$ \\
\hline 1 & $\mathrm{NiFeW}\left(30^{\circ} \mathrm{C}\right)$ & 128 \\
\hline 2 & $\mathrm{NiFeW}\left(\right.$ Annealed $\left.200^{\circ} \mathrm{C}\right)$ & 142 \\
\hline
\end{tabular}

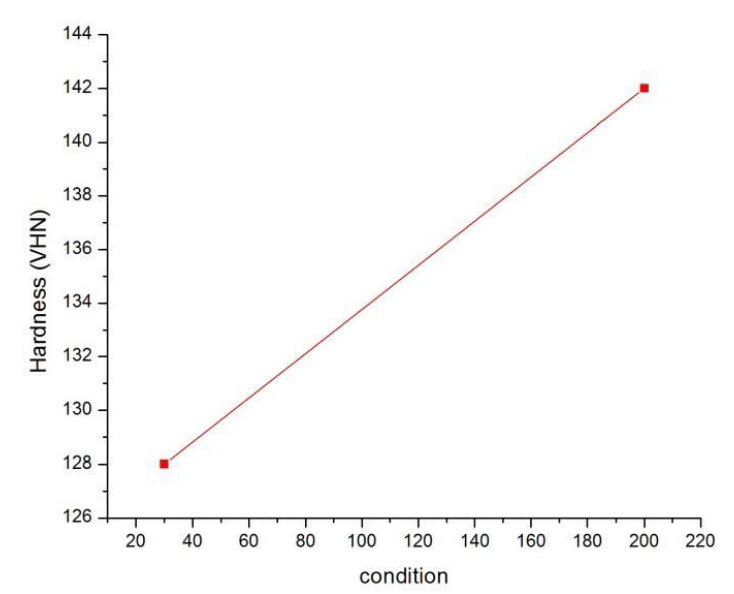

Fig.4: Hardness changes with condition

\section{Conclusion}

An alloy thin films $\mathrm{NiFeW}$ has been prepared by electro deposition method. The characteristics of NiFeW films were observed. From EDAX result, boron increased and nickel decreased after annealing. The XRD results of $\mathrm{NiFeW}$ films have shown face centered cubic phase with three diffraction peaks. The thin films prepared with annealing process are bright and uniformly coated on the surface. They are crack free by appearance. The hardness values of thin films after annealing process increases.

\section{References}

[1] N. Gupta, A. Verma, S.C. Kashyap, Dielectric behavior of spin-deposited nano crystalline nickel-zinc ferrite thin films processed by citrate-route, Solid State Commun. 10 (2005) 689-694.

[2] K. Sridharan, K. Sheppard, Electrochemical characterization of Fe-Ni-P alloy electrodeposition, J. Appl. Electrochem. 27 (1997) 1198-1206.

[3] N. Gupta, A. Verma, S.C. Kashyap, Dielectric behavior of spin-deposited nanocrystalline nickel-zinc ferrite thin films processed by citrate-route, Solid State Commun. 10 (2005) 689-694.

[4] E. Jartych, M. Jalochowski, M. Budzynski, Influence of the electrodeposition parameters on surface morphology and local magnetic properties of thin iron layers, Appl. Surf. Sci. 193 (2002) 210-216.

[5] Y. Motomura, T. Tatsumi, H. Urai, M. Aoyama, Soft magnetic properties and heat stability for $\mathrm{Fe} / \mathrm{NiFe}$ super lattices, IEEE Transactions on Magnetics 26 (1990) 2327-2331.

[6] Y. Chen, Q.P. Wang, C. Cai, Y.N. Yuan, F.H. Cao, Z. Zhang, J.Q. Zhang, Electrodeposition and characterization of nanocrystalline CoNiFe films, Thin Solid Films, 520 (2012) 3553-3557.

[7] L. Chih-Huang, H. Matsuyama, R.L. White, T.C. Anthony, Anisotropic exchange for NiFe films grown on epitaxial NiO, IEEE Transactions on Magnetics 31(6) (1995) 2609-2611.

[8] Sulztanu, N.; Fbrinza, J.; Electrodeposited Ni-Fe-S films with high resistivity for Magnetic recording devices, J. Optoelectron Adv Mat., 2004, 6, 641- 645.

[9] Esther, P.; Joseph Kennady,C.; Effect of sodium tungstate on the properties of Electrodeposited nanocrystalline $\mathrm{NiFeCr}$ films, Journal of Non Oxide Glasses., 2010, 1, 35-44.

[10] C.Z. Yao, P. Zhang, M. Liu, G.R. Li, J.Q. Ye, P. Liu, Y.X. Tong, Electrochemical preparation and magnetic study of Bi-Fe-Co-Ni-Mn high entropy alloy, Electrochim. Acta. 53 (2008) 8359-8365

[11] M. Bedir, O.F. Bakkaloglu, I.H. Karahan, M. Oztas, A study on electrodepisted NixFe1-x alloy films,Pramana. 66(6) (2006) 1093-1104.

[12] Myung, N.; A Study on the Electrodeposition of NiFe Alloy Thin Films Using Chronocoulometry and Electrochemical Quartz Crystal Microgravimetry, Bull. Korean Chem. Soc., 2001, 22, 994-998

[13] Emerson, R.N.; Kennady, C.J.;.Ganesan, S.; Effect of Organic additives on the Magnetic properties of Electrodeposition of CoNiP Hard Magnetic Films, Thin solid films, 2007,515, 3391-3396.

[14] Sulztanu, N.; Fbrinza, J.; Electrodeposited Ni-Fe-S films with high resistivity for Magnetic recording devices, J. Optoelectron Adv Mat., 2004, 6, 641- 645.

[15] Hamid, Z.A.; Electrodeposition of Cobalt- Tungsten Alloys from Acidic Bath Containing Cationic Surfactants, Materials Letters,2003, 57, 2558.

[16] Y. Motomura, T. Tatsumi, H. Urai, M. Aoyama, Soft magnetic properties and heat stability for $\mathrm{Fe} / \mathrm{NiFe}$ super lattices, IEEE Transactions on Magnetics 26 (1990) 2327-2331.

[17] Kannan, R.; Ganesan, S.; Selvakumari ,T.M.; Synthesis and characterization of nano crystalline NiFeWS thin films in diammonium citrate bath, Digest journal of nanomaterials and biostructures, 2012,7, 1039-1050. 